\title{
Oposições múltiplas: abordagem contrastiva para sujeitos com desvio fonológico
}

\author{
Marizete Ilha Ceron
}

Ceron MI. Oposições múltiplas: abordagem contrastiva para sujeitos com desvio fonológico [dissertação]. Santa Maria (RS): Universidade Federal de Santa Maria; 2009.

Este estudo teve como objetivo aplicar e testar o Modelo de Oposições Múltiplas em crianças falantes do Português Brasileiro com diferentes gravidades do desvio fonológico. O grupo pesquisado foi constituído por cinco sujeitos: dois do sexo masculino e três do feminino, com idade média de seis anos e um mês no início do tratamento. O diagnóstico de desvio fonológico foi determinado pelas avaliações fonoaudiológicas e exames complementares. Os dados da fala dos sujeitos foram coletados e analisados por meio da avaliação fonológica, antes e depois do tratamento. Após as avaliações, os sujeitos foram submetidos à fonoterapia pelo Modelo de Oposições Múltiplas durante 25 sessões. Analisou-se o progresso terapêutico no que se refere aos inventários: fonético e fonológico, aos traços distintivos enfocados na terapia a partir dos sons-alvo, bem como as mudanças no Percentual de Consoantes Corretas - Revisado (PCC-R) e os tipos de generalizações obtidas (itens lexicais não utilizados no tratamento, para outra posição na palavra, dentro de uma classe de sons, para outras classes de sons). Verificou-se um aumento estatisticamente significante do número de sons no inventário fonético, de fonemas no inventário fonológico, assim como uma diminuição estatisticamente significante do número de traços distintivos alterados. Houve diferença estatisticamente significante no PCC-R e, em alguns tipos de generalização (itens lexicais não utilizados no tratamento, para outra posição da palavra e para outras classes de sons). Não houve diferença estatística para a generalização dentro de uma classe de sons, porém observou-se um aumento do percentual na avaliação final. Assim, pôde-se concluir que o Modelo de Oposições Múltiplas foi efetivo para o tratamento de sujeitos falantes do português brasileiro; proporcionou aquisições de sons no inventário fonético e de fonemas no inventário fonológico, um aumento no PCC-R e em todos os tipos de generalizações (itens lexicais não utilizados no tratamento, para outra posição na palavra, dentro de uma classe de sons, para outras classes de sons). Os sujeitos, cujos sons-alvo contemplavam o trabalho com a maioria dos traços alterados e com sons mais complexos na hierarquia, apresentaram maior número de aquisições em seus inventários fonológicos.

Dissertação apresentada ao Programa de Pós-Graduação em Distúrbios da Comunicação Humana da Universidade Federal de Santa Maria para obtenção de título de Mestre em Distúrbios da Comunicação Humana, sob orientação da Profa. Dra. Márcia Keske-Soares.

(1) Mestre, Fonoaudióloga do Programa de Residência Multiprofissional Integrada em Sistema Público de Saúde (RMISPS) da Universidade Federal de Santa Maria. Santa Maria (RS), Brasil.

Endereço para correspondência: Marizete Ilha Ceron. R. Bentevi, 215, Bairro JK, Santa Maria (RS), Brasil, CEP: 97035-130. E-mail: marizeteceron@hotmail.com 